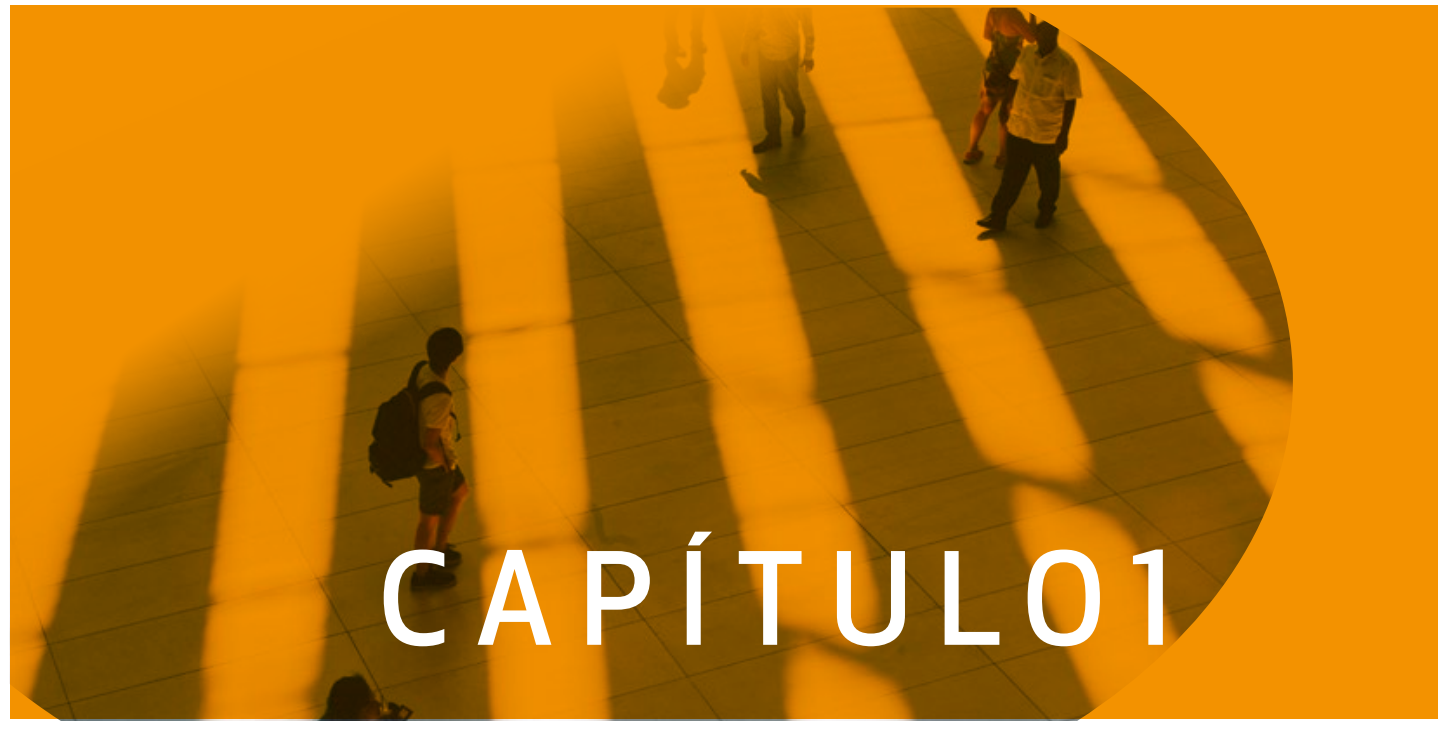





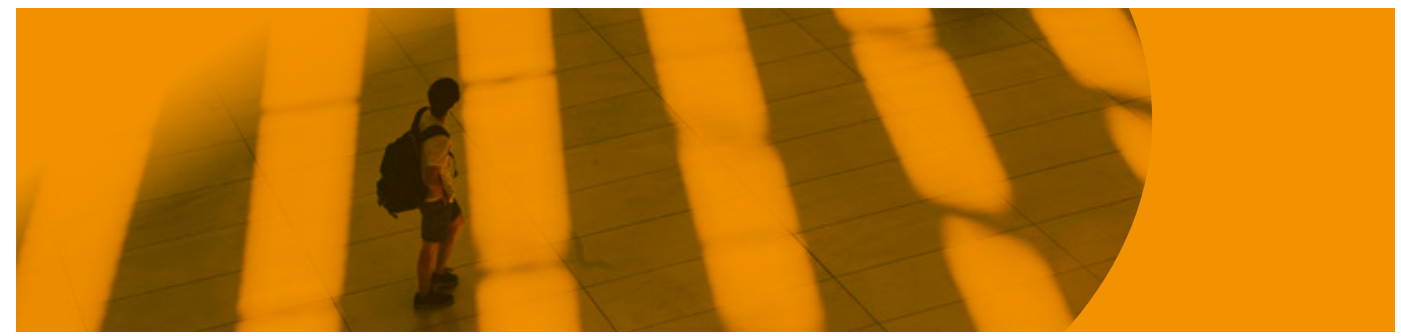

\title{
Contexto de desarrollo de la educación superior contable en Colombia
}

\author{
Martha Lucía Fuertes Díaz ${ }^{1}$ \\ José Obdulio Cúrvelo Hassán²
}

1 Doctora en Administración Gerencial (C), Universidad Benito Juárez, México. Magíster en Administración con énfasis en Finanzas Corporativas, Universidad ICESI, Colombia. Especialista en Finanzas con Concentración en Finanzas Avanzadas, Universidad ICESI, Colombia. Contadora Pública, Universidad Santiago de Cali, Colombia. Docente Universidad Nacional Abierta y a Distancia, UNAD, Colombia. Investigadora principal Grupo de Investigación ilama.

Correo electrónico: martha.fuertes@unad.edu.co

Orcid: http://orcid.org/0000-0001-8468-1867

Google Scholar: https://scholar.google.com.co/citations?user=IP5s-

2 Doctor en Contabilidad, Universidad de Valencia, España. Magíster en Filosofía, Universidad Santo Tomás, Colombia. Especialista en Revisoría Fiscal y Control de Gestión, Universidad Cooperativa, Colombia. Contador público, Universidad Cooperativa, Colombia. Decano Nacional de las Facultades de Contaduría pública de la Universidad Cooperativa de Colombia. Director del Grupo de Investigación Contabilidad y Entorno Social. Correo electrónico: jose.curvelo@ucc.edu.co 


\section{Introducción}

El conocimiento contable se constituye como un saber en continua evolución, ha estado presente en todas las etapas de desarrollo de la humanidad, desde tiempos remotos hasta el presente, ha exigido una constante dinámica de cambio en sus concepciones internas para responder pertinentementeal objeto central de estudio en un contexto social que evoluciona permanentemente.

En este proceso de desarrollo social y mercantil, en un contexto altamente competitivo, globalizado y en constante evolución tecnológica; ha sido determinante la evolución del conocimiento contable, que ha pasado desde la percepción instrumental, a una concepción centrada en lo técnico contable, hasta su percepción desde un enfoque lógico formal, tal como lo afirman Mejía, Mora y Montes (2013).

Este proceso continuo de evolución del conocimiento contable se aprecia en la evolución de la epistemología contable, partiendo de la concepción descrita por Mejía, et al. (2013) que la definen como:

La contabilidad es un saber dinámico, en constante movimiento en sus estructuras internas y en su relación externa con su objeto formal de estudio: la valoración cualitativa y cuantitativa de la existencia y circulación de la riqueza ambiental, social y económica controlada por las organizaciones. La ubicación de la contabilidad en el campo del conocimiento ha devenido en su calificación como arte, técnica, tecnología social, hasta las más modernas concepciones que fundamentan su adscripción al campo de las ciencias. (p.160).

Es así como hasta la década de los años sesenta, la concepción y reconocimiento del pensamiento contable se orienta a lo instrumental, lo operativo que se concentra en lo técnico contable. Como lo señalan Mejía, et al. (2013), esta tendencia cambia en la década de los años setenta, cuando se aprecia una gran preocupación por la concepción "lógico-formal" del conocimiento contable percibido ya como ciencia. Este período se convierte en "la edad de oro de la 
investigación a priori de la contabilidad", que en las siguientes décadas permite la formación de la teoría contable, establece el campo del conocimiento, el objeto de estudio material, el objeto de estudio formal, método, naturaleza, función y finalidad de la contabilidad, que se concibe como:

[...] un saber dinámico que progresa en función de los cambios de las condiciones sociales y del avance de otros campos del saber que contribuyen al surgimiento no solo de otras explicaciones de la realidad, sino al establecimiento de nuevas condiciones para su transformación en función de los actuales requerimientos ambientales, sociales y económicos. (Mejía, et al., 2013, p.162).

Finalmente, se resalta como Cañibano (1979) aporta para la definición de contabilidad su percepción como ciencia económica. Su aporte se orienta en tres enfoques: explicativo, predictivo y de control, propuesto por en la siguiente definición:

La contabilidad es una ciencia de naturaleza económica, cuyo objeto es el conocimiento pasado, presente y futuro de la realidad económica, en términos cuantitativos a todos sus niveles organizativos, mediante métodos específicos, apoyados en bases suficientemente contrastadas, a fin de elaborar una información que cubra las necesidades financieras, de planificación y control. (p. 33).

Este proceso de evolución y desarrollo del conocimiento contable se ha generado como respuesta a las necesidades surgidas desde las dinámicas de desarrollo social y mercantil de las sociedades en el contexto global. Se constituye así el conocimiento contable en una base fundamental que aportó para alcanzar el actual desarrollo mercantil que se aprecia en el desarrollo de los negocios, la sociedad y el Estado.

En este proceso de desarrollo, específico para el caso colombiano, se debe tener conciencia de la diversidad regional del país, de sus comunidades sociales caracterizadas por dinámicas económicas y sociales diferentes, que a su vez 
están impactadas por un ambiente altamente globalizado. Esto requiere que la educación del profesional en contabilidad considere su aporte para la gestión integral de las organizaciones, que se oriente en la formación de profesionales competentes disciplinarmente, con fundamento ético, responsabilidad social y ambiental. Para avanzar en la formación de profesionales generadores de impacto social y económico tendientes al logro de mayores estándares de bienestar social y económico para el país.

Precisamente, se hace necesario sensibilizarse sobre el desarrollo del conocimiento contable en nuestro país, cómo es percibido por las instituciones de educación superior, cómo orientan sus planes de estudio y cómo proponen el desarrollo de competencias en los futuros profesionales de la Contaduría Pública en Colombia.

Este análisis va a constituirse en el punto de partida para ser comparado con el desarrollo de la educación profesional contable en el contexto internacional. Esta comparación permitirá establecer la naturaleza, favorable o desfavorable, acertada o desacertada, de las actuales propuestas educativas en el país en la formación profesional de los contadores públicos.

\section{La política pública como marco regulatorio en los programas de contaduría pública}

Para el desarrollo de programas profesionales de contaduría pública en Colombia, se debe considerar la política pública vigente desde la cual se establecen lineamientos y regulación dada la función social que le es implícita a los profesionales de esta disciplina, que obligatoriamente debe ser acogida.

En la figura 1 se presenta el compilado de normas que regula tanto la educación profesional, como el desempeño de los profesionales de este campo del conocimiento. Tanto en el contexto nacional como internacional. 

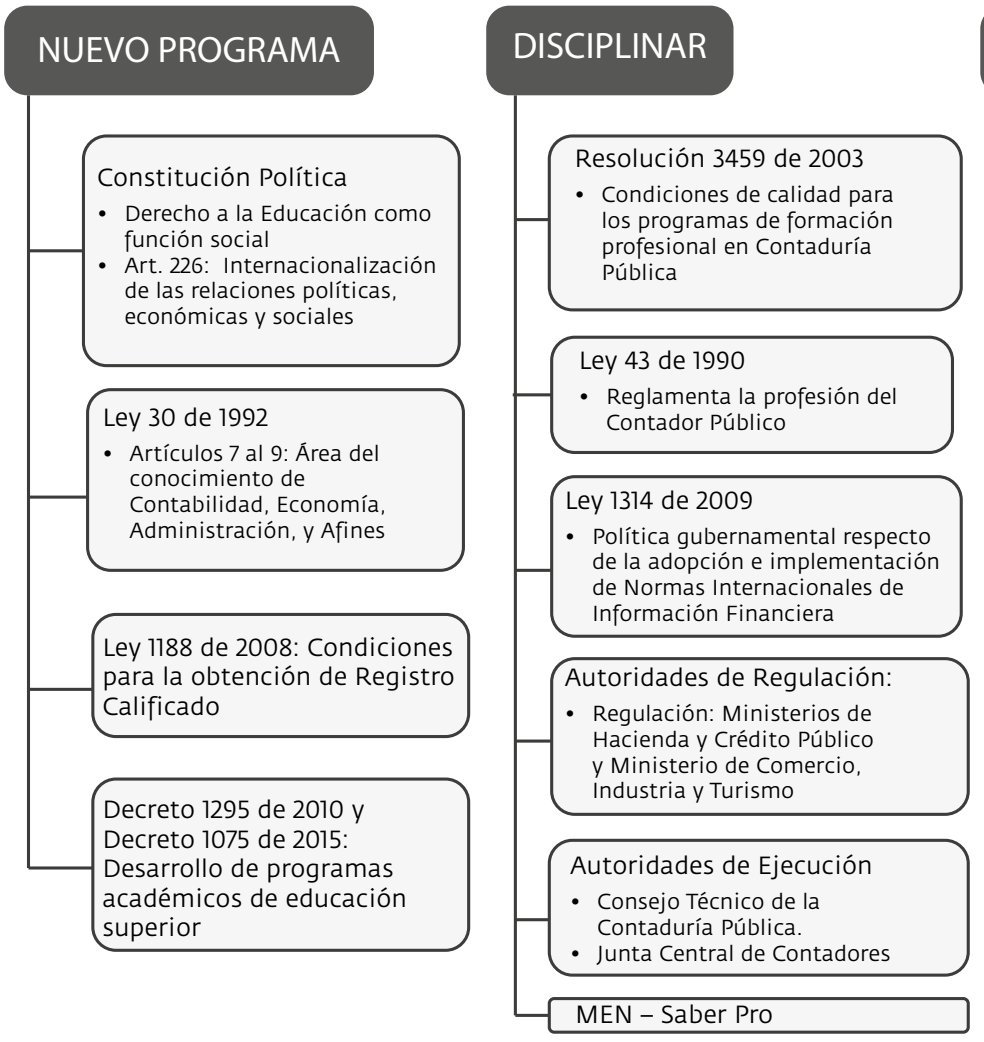

\section{INTERNACIONAL}

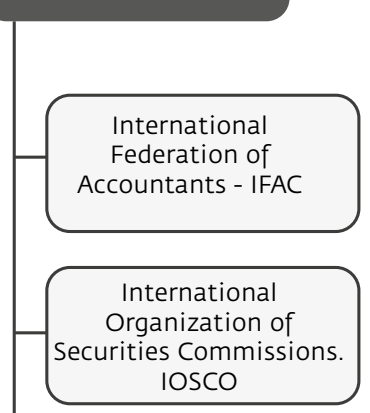

Política gubernamental respecto la adopción e implementación de Normas Internacionales de nformación Financiera

International Accounting Standards Board-IASB: IFRS NIIF y NIA Hacienda y Crédito Público yinisterio de Comercio,

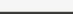

Congreso de Bolonia

Figura 1. Política pública para programas profesionales de contaduría pública.

Fuente: elaboración propia

Se debe partir del reconocimiento de los postulados de la Constitución Política de Colombia, donde se señala el derecho a la educación de la población como función social que le corresponde al Estado garantizar.

En materia de educación contable, se considera especialmente lo establecido a partir de la Ley 30 de 1992, que en sus artículos 7, 8 y 9 permite ubicar el programa dentro del área del conocimiento de contabilidad, economía, administración, y afines.

En Colombia, todo programa de educación superior debe contar con el correspondiente registro calificado que otorga el Ministerio de Educación Nacional. 
Se expide con vigencia de siete años y su renovación permite ejercer labor de control como garantía para el mejoramiento continuo y la calidad de los programas de educación superior.

Es así como la Ley 1188 de 2008, generada desde el Congreso de la República de Colombia, regula las condiciones para el otorgamiento de registro calificado para los programas de educación superior.

Por su parte, el Ministerio de Educación Nacional, a través del Decreto 1295 de 2010, reglamenta el registro calificado, la oferta y desarrollo de programas académicos de educación superior y sus condiciones de calidad.

El Decreto 1075 de 2015, expedido por el Ministerio de Educación Nacional, como Decreto Único Reglamentario del Sector Educación, unifica la política pública para el sector educativo colombiano; y, en su capítulo 2, reglamenta el registro calificado y los requisitos para los programas de pregrado.

Desde el Ministerio de Educación Nacional, mediantela Resolución 3459 de2003, se reglamentan las condiciones de calidad que deben observar los programas de formación profesional en contaduría pública en Colombia, para su ofrecimiento y desarrollo ante la comunidad. Sus principios y propósitos deben orientarse hacia la formación integral y competente de los futuros profesionales.

En la parte disciplinar, el Congreso de la República el 13 de diciembre de 1990, aprueba la Ley 43, que reglamenta la profesión del Contador público en el país, y señala en su artículo 1 la definición legal de contador público como:

Se entiende por Contador público la persona natural que, mediante la inscripción que acredite su competencia profesional en los términos de la presente Ley, está facultada para dar fe pública de hechos propios del ámbito de su profesión, dictaminar sobre estados financieros, y realizar las demás actividades relacionadas con la ciencia contable en general. 
Otro aspecto a resaltar en esta ley se establece en su artículo 2, con la exigencia de contadores públicos para el desarrollo de actividades relacionadas con la ciencia contable en general, como:

[...] la organización, revisión y control de contabilidades, certificaciones y dictámenes sobre estados financieros, certificaciones que se expidan con fundamentos en los libros de contabilidad, revisoría fiscal prestación de servicios de auditoría, así como todas aquellas actividades conexas con la naturaleza de la función profesional del Contador Público, tales como: la asesoría tributaria, la asesoría gerencial, en aspectos contables y similares.

Un momento histórico, por el cambio estructural en el campo del conocimiento contable, se estableció a partir de la Ley 1314 de 2009, desde la cual se establece la adopción eimplementación de Normas Internacionales de Información Financiera (NIIF) y de los principios y normas de contabilidad e información financiera y de aseguramiento de la información aceptadas en el país, a partir de los estándares de aplicación mundial (Fuertes, 2018).

Esta ley, expedida desde el Congreso de la República, está orientada a la regulación de los principios y normas de contabilidad e información financiera y de aseguramiento de información aceptados en Colombia, se señalan las autoridades competentes, el procedimiento para su expedición y se determinan las entidades responsables de vigilar su cumplimiento.

La Ley 1314 de 2009 se orienta a establecer un sistema único y homogéneo a partir de las normas contables de información financiera y de aseguramiento de la información. La cual, como se señala su artículo 1, se fundamenta en el propósito de lograr estados financieros que:

[...] brinden información financiera comprensible, transparente y comparable, pertinente y confiable, útil para la toma de decisiones económicas por parte del Estado, los propietarios, funcionarios y empleados de las empresas, los inversionistas actuales o potenciales 
y otras partes interesadas, para mejorar la productividad, la competitividad y el desarrollo armónico de la actividad empresarial de las personas naturales y jurídicas, nacionales o extranjeras.

Así, desde la política pública se regulan en Colombia los marcos conceptuales aplicables en materia contable, a partir de los estándares propuestos desde la International Accounting Standards Boards (IASB) o Junta de Normas Internacionales de Contabilidad, como organismo de carácter privado que se encarga de desarrollar y aprobar las International Financial Reporting Standards (IFRS) o Normas Internacionales de Información Financiera (NIIF).

La Fundación IFRs desarrolla los estándares IFRs ${ }^{\circledR}$ para avanzar en la confianza, transparencia, responsabilidad y eficiencia de los mercados financieros de todo el mundo, busca que mediante su acogida se establezca la generación de los informes financieros. Como esfuerzo de interés público orientado al fomento de la confianza, el crecimiento y la estabilidad financiera a largo plazo en la economía global. En materia de aseguramiento de la información se acogen los marcos conceptuales propuestos desde la International Federation of Accountants (IFAC) o Federación Internacional de Contadores.

La International Federation of Accountants (IFAC) o Federación Internacional de Contadores, es reconocida como organización global de la profesión contable para proteger y servir el interés público, y está orientada al fortalecimiento de la profesión para contribuir al desarrollo de economías internacionales. La IFAC participa activamente en el establecimiento de las normas internacionales para:

- Auditoría y aseguramiento de la información.

- Educación y contabilidad.

- Ética para contadores.

- Normas internacionales de contabilidad del sector público.

Los anteriores marcos conceptuales de información contable y de aseguramiento de la información son armonizados en Colombia bajo los conceptos del Concejo Técnico de la Contaduría pública (СтCP). A partir de 
la Ley 1314 de 2008 se emana una importante cantidad de decretos hasta llegar al establecimiento del Decreto 2420 y el Decreto 2496 , ambos del año 2015, que son los que actualmente regulan la contabilidad bajo Normas de Información Financiera y de aseguramiento vigentes en Colombia, y de otros subsecuentes pero complementarios.

Además, la Ley 1314 de 2009, en su artículo 6, señala las facultades regulatorias en materia de contabilidad a cargo de la Contaduría General de la Nación, Ios Ministerios de Hacienda y Crédito Público y de Comercio, Industria y Turismo; y como organismo de normalización técnica de las normas contables de información financiera y de aseguramiento de la información se designa al CTCP.

Es importante considerar otro referente derivado de la política pública que debe ser considerado en el momento de realizar propuestas o realizar solicitud de renovación de registro calificado de programas de contaduría pública. Este corresponde a las pruebas Saber Pro, que desde su módulo de información y control contable evalúa a los futuros profesionales de la contaduría pública, fundamentales para definir las competencias para el eficiente desempeño del futuro profesional.

Por lo anterior, en las propuestas de nuevos programas o renovaciones de los programas existentes de contaduría pública, se debe observar el abundante marco regulatorio establecido desde la política pública para la aplicación y desarrollo del conocimiento contable. Desde sus lineamientos para la educación contable, y disciplinariamente en la aplicación de los estándares internacionales de información financiera y de aseguramiento de la información, los cuales implica un alto nivel regulatorio en materia disciplinar. También, el marco regulatorio que se orienta al desempeño ético de los profesionales de esta disciplina en sus diferentes actuaciones. Finalmente, en políticas públicas tendientes a garantizar la confianza que le es inherente a los profesionales que se desempeñan como contadores públicos.

Como se puede apreciar, de acuerdo con los aspectos identificados, en Colombia la educación superior en contaduría pública implica una profesión ampliamente 
regulada, desde múltiples enfoques. Representa un alto estándar de exigencia al momento de proponer nuevos programas o renovar los registros calificados de los ya existentes.

Además de la política pública que debe ser observada al momento de proponer o renovar propuestas académicas para los programas de contaduría pública, también se deben sumar la política institucional desde donde se propone el programa, para que la propuesta de formación profesional que se realiza sea coherente y se armonice con la misión y visión institucional, el proyecto académico pedagógico, el proyecto educativo de la escuela o facultad a la cual está o estará adscrito el programa. Aspectos todos que van a aportar al logro de la formación integral de los futuros profesionales de la contaduría pública, sobre una base científica, ética y humanista que aporte significativamente al desarrollo de las organizaciones, el desarrollo social y humano de la comunidad, en el ámbito local, regional y nacional y global.

\section{Estado actual de la educación contable en el ámbito internacional}

La contaduría es una disciplina que se inserta en los procesos de globalización, con su tendencia a hacer homogéneos los procesos, así como la educación y las prácticas contables que se estandarizan para asegurar la armonización de la circulación de capitales y flujos comerciales como base de la internacionalización y la globalización de la economía (Ley 1314 de 2009).

Es así como la evolución de la contaduría se ha dado como respuesta a los retos y necesidades resultado de la globalización y los elevados estándares de competitividad que enfrenta todo tipo de organización en el ámbito mundial, por lo que se requiere del análisis del comportamiento y la educación en el área del programa en el escenario internacional.

Con este propósito, se adelantó una revisión empírica en las páginas web de las universidades de los Estados Unidos, Europa y América Latina que son 
referentes en la oferta de programas contables, tanto a nivel de pregrado como a nivel de formación posgradual.

Para identificar las universidades objeto de estudio, se tomó la información del ranking que arroja el académico World Universities Ranking, y para el caso de las universidades latinas se consultó el Latin American Ranking.

El criterio para seleccionar en el Academic Ranking of World Universities, se centra en su modelo, el cual realiza la valoración de un conjunto de indicadores, objetivos y datos de terceros en los que se tiene en cuenta el número de alumnos, profesores que han ganado premios nobel y medallas Fields, número de investigadores altamente citados, número de artículos publicados en revistas de Nature y Science el número de artículos indexados en Science Citation Index - Expanded y Social Sciences Citation Index, y el rendimiento per cápita.

Para la selección de los programas que se analizaron en las siguientes tablas, se identificaron los siguientes aspectos:

- Que la universidad cuente con un programa en el área contable.

- La valoración en el ranking del programa en el área contable de manera significativa.

- El programa debe estar vigente y no tener vencimiento de vigencias de la oferta en el futuro próximo.

- Que disponga de información amplia y suficiente sobre la oferta en su sitio Web oficial sobre el programa del área del conocimiento.

De acuerdo con los anteriores parámetros, se identificaron los mejores tres programas de Europa, los mejores nueve programas en América Latina, y los mejores programas de Estados Unidos, China y Australia. Los programas seleccionados se ilustran en la figura 2. 


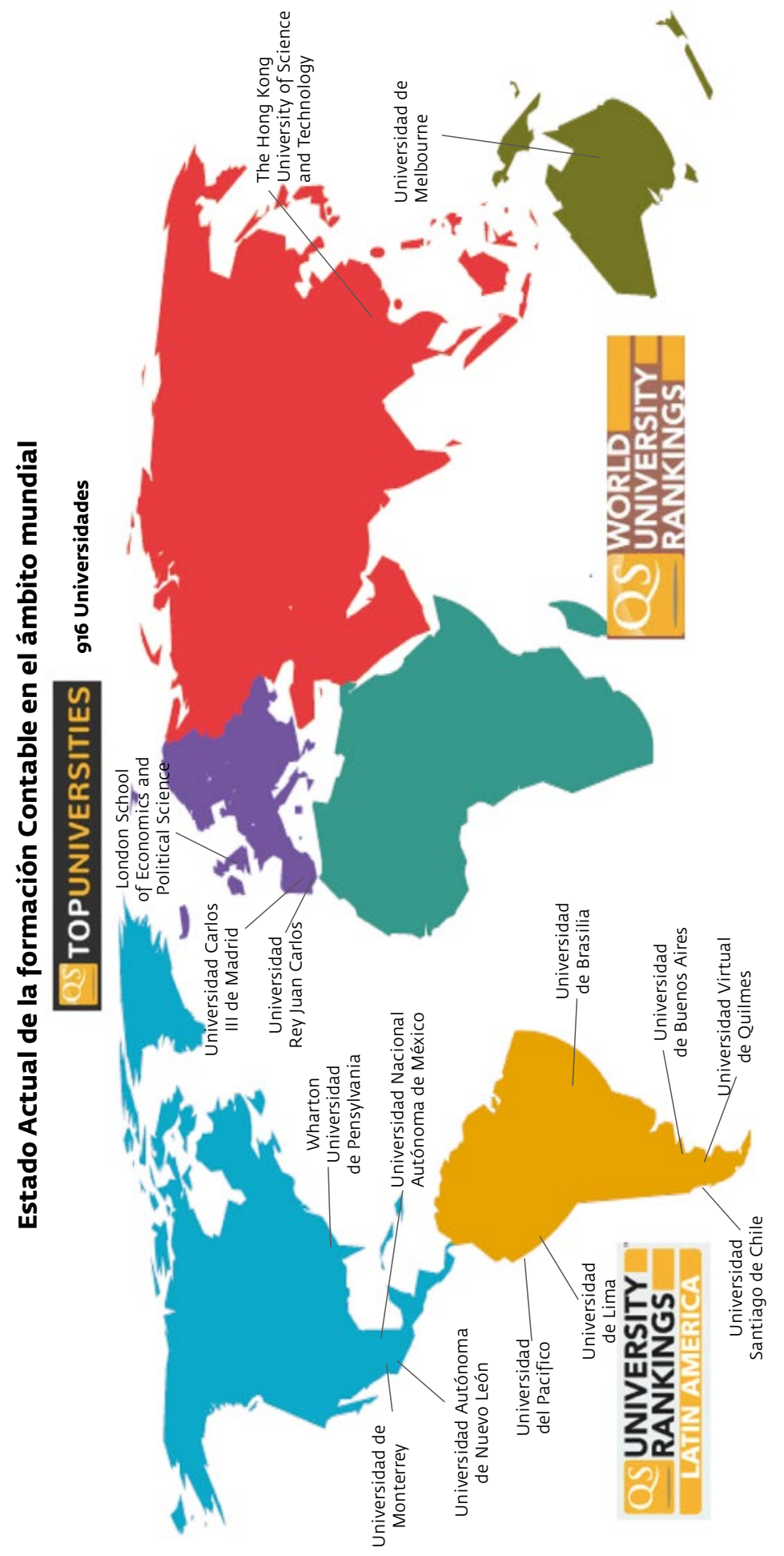

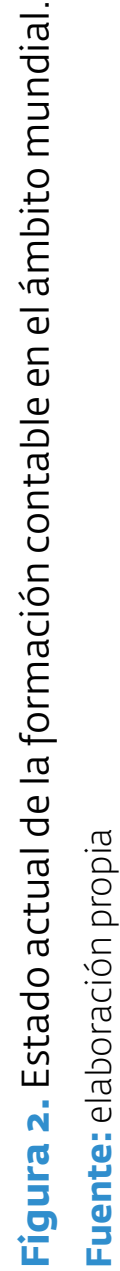


En la tabla 1 se presentan de manera resumida los aspectos representativos que se identificaron en cada programa seleccionado de América Latina. Previa consulta realizada en las respectivas páginas web institucionales. Tabla 1. Universidades con programas del área de conocimiento
en América Latina.

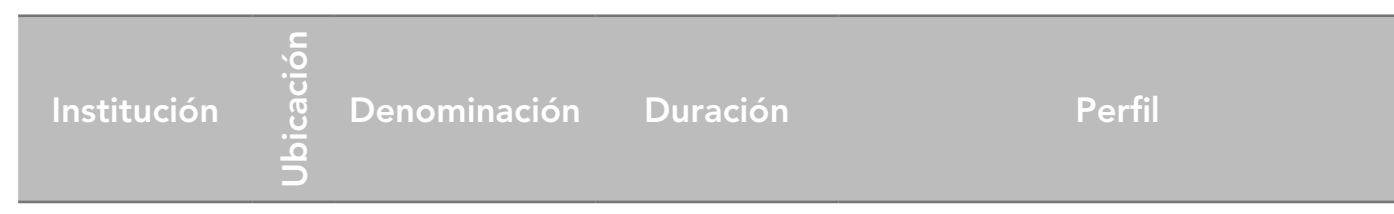

\begin{tabular}{|c|c|c|c|c|}
\hline $\begin{array}{l}\text { Universidad } \\
\text { de Buenos }\end{array}$ & 畩 & $\begin{array}{l}\text { Contador } \\
\text { público }\end{array}$ & 5 años & $\begin{array}{l}\text { Gestor de instituciones financieras, } \\
\text { analista y auditor en el área }\end{array}$ \\
\hline
\end{tabular}

\begin{tabular}{|c|c|c|c|c|}
\hline $\begin{array}{c}\text { Universidad } \\
\text { Santiago de } \\
\text { Chile }\end{array}$ & $\frac{\frac{0}{C}}{U}$ & $\begin{array}{l}\text { Contador } \\
\text { público y } \\
\text { Auditor }\end{array}$ & 10 semestres & $\begin{array}{l}\text { Generar información para la toma de } \\
\text { decisiones y control. } \\
\text { Líder, emprendedor y con habilidades } \\
\text { para el trabajo en equipo }\end{array}$ \\
\hline $\begin{array}{l}\text { Universidad } \\
\text { de Brasilia }\end{array}$ & $\begin{array}{l}\overline{\bar{n}} \\
\overline{\frac{\pi}{n}} \\
\bar{\infty}\end{array}$ & $\begin{array}{l}\text { Licenciatura en } \\
\text { Contaduría }\end{array}$ & 8 semestres & $\begin{array}{l}\text { Analista y Auditor. Habilidades de } \\
\text { comunicación y trabajo en equipo. }\end{array}$ \\
\hline $\begin{array}{l}\text { Universidad } \\
\text { de Monterrey }\end{array}$ & 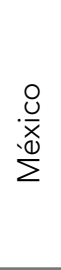 & $\begin{array}{c}\text { Licenciatura en } \\
\text { Contaduría y } \\
\text { Finanzas }\end{array}$ & $\begin{array}{l}330 \text { créditos } \\
\text { (55 asignaturas) }\end{array}$ & $\begin{array}{l}\text { Capacidades de planeación y análisis } \\
\text { Experto en presentación e } \\
\text { interpretación de información } \\
\text { financiera objetiva y oportuna } \\
\text { Toma estratégica de decisiones } \\
\text { responsables. }\end{array}$ \\
\hline $\begin{array}{l}\text { Universidad } \\
\text { Nacional } \\
\text { Autónoma de } \\
\text { México }\end{array}$ & 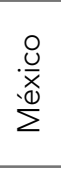 & $\begin{array}{l}\text { Licenciatura en } \\
\text { Contaduría }\end{array}$ & 8 semestres & $\begin{array}{l}\text { Enfocado en Solución de } \\
\text { problemáticas económicas, análisis y } \\
\text { planeación, toma } \\
\text { de decisiones, }\end{array}$ \\
\hline $\begin{array}{l}\text { Universidad } \\
\text { Autónoma de } \\
\text { Nuevo León }\end{array}$ & $\begin{array}{l}\stackrel{O}{U} \\
\stackrel{x}{X} \\
\sum\end{array}$ & $\begin{array}{l}\text { Contaduría } \\
\text { pública }\end{array}$ & 10 semestres & $\begin{array}{l}\text { Perfil integral fundamentado en la } \\
\text { ética profesional, trabajo colaborativo } \\
\text { y la responsabilidad social y } \\
\text { humanista. }\end{array}$ \\
\hline $\begin{array}{l}\text { Universidad } \\
\text { del Pacifico }\end{array}$ & $\frac{0}{\sqrt[0]{2}}$ & $\begin{array}{l}\text { Licenciatura en } \\
\text { Contaduría }\end{array}$ & 10 ciclos & $\begin{array}{l}\text { Gestionar información financiera, } \\
\text { tributaria y de costos, contribuyendo } \\
\text { al desarrollo eficiente de las } \\
\text { organizaciones. }\end{array}$ \\
\hline
\end{tabular}




\begin{tabular}{|c|c|c|c|c|}
\hline Institución & $\frac{\frac{5}{3}}{\frac{0}{3}}$ & Denominación & Duración & Perfil \\
\hline & & & & $\begin{array}{l}\text { Desenvolverse en entornos } \\
\text { económicos globales }\end{array}$ \\
\hline $\begin{array}{l}\text { Universidad } \\
\text { de Lima }\end{array}$ & $\frac{\sqrt{2}}{2}$ & $\begin{array}{l}\text { Licenciatura } \\
\text { en Contaduría }\end{array}$ & 10 semestres & $\begin{array}{l}\text { Proponer soluciones de negocios } \\
\text { a partir del entendimiento e } \\
\text { interpretación de hechos económicos } \\
\text { y financieros de las organizaciones. }\end{array}$ \\
\hline
\end{tabular}

Universidad

Virtual de

Quilmes
Contador público

Nacional
Diseño, implementación y evaluación

330 créditos

$(40$ asignaturas)

5 años del sistema contable de cualquier organización.

Analizar e interpretar la información contable y financiera para la toma de decisiones de los distintos usuarios.

Fuente: elaboración propia

En la tabla 2 se presentan de manera resumida los aspectos representativos que se identificaron en cada programa seleccionado de Europa, previa consulta realizada en las respectivas páginas web institucionales.

Tabla 2. Universidades con programas del área de conocimiento en Europa.

\begin{tabular}{|c|c|c|c|c|}
\hline Institución & Ubicación & Denominación & Duración & Perfil \\
\hline $\begin{array}{l}\text { London School } \\
\text { of Economics } \\
\text { and Political } \\
\text { Science }\end{array}$ & $\begin{array}{l}\text { Reino } \\
\text { Unido }\end{array}$ & $\begin{array}{l}\text { Licenciatura en } \\
\text { Contabilidad y } \\
\text { Finanzas }\end{array}$ & 4 años & $\begin{array}{l}\text { Banca de inversión, análisis } \\
\text { de inversiones, consultoría de } \\
\text { gestión y la gestión financiera }\end{array}$ \\
\hline $\begin{array}{l}\text { Universidad } \\
\text { Carlos III de } \\
\text { Madrid }\end{array}$ & España & $\begin{array}{l}\text { Grado en } \\
\text { Finanzas y } \\
\text { Contabilidad }\end{array}$ & $\begin{array}{l}4 \text { años } \\
\text { (240 } \\
\text { créditos) }\end{array}$ & $\begin{array}{l}\text { Análisis y gestión de inversiones, } \\
\text { banca, auditoría, consultoría y } \\
\text { gestión financiera, formación } \\
\text { integral gerencial. }\end{array}$ \\
\hline $\begin{array}{l}\text { Universidad } \\
\text { Rey Juan } \\
\text { Carlos }\end{array}$ & España & $\begin{array}{l}\text { Grado en } \\
\text { Contabilidad y } \\
\text { Finanzas }\end{array}$ & $\begin{array}{l}4 \text { años } \\
\text { (240 } \\
\text { créditos) }\end{array}$ & $\begin{array}{l}\text { Conocimientos técnicos en } \\
\text { Contabilidad, Finanzas y } \\
\text { Organización de Empresas, } \\
\text { complementado con formación } \\
\text { matemática, estadística y } \\
\text { jurídica. }\end{array}$ \\
\hline
\end{tabular}

Fuente: elaboración propia 
En la tabla 3 se presentan de manera resumida los aspectos representativos que se identificaron en cada programa seleccionado de Estados Unidos, Asia y Pacífico, previa consulta realizada en las respectivas páginas web institucionales.

Tabla 3. Universidades con programas del área de conocimiento en Estados Unidos, Asia y Pacífico.

\begin{tabular}{|c|c|c|c|c|}
\hline Institución & Ubicación & Denominación & Duración & Perfil \\
\hline $\begin{array}{l}\text { Wharton } \\
\text { University of } \\
\text { Pennsylvania }\end{array}$ & U.S.A. & Accounting & 4 años & $\begin{array}{l}\text { Enfoque en planificación } \\
\text { de impuestos, auditoría, } \\
\text { contabilidad internacional, } \\
\text { toma de decisiones y el control } \\
\text { de fusiones y adquisiciones, }\end{array}$ \\
\hline $\begin{array}{l}\text { The Hong } \\
\text { Kong } \\
\text { University of } \\
\text { Science and } \\
\text { Technology }\end{array}$ & China & $\begin{array}{l}\text { Licenciado en } \\
\text { Contabilidad }\end{array}$ & 4 años & $\begin{array}{l}\text { Enfocado en los principios } \\
\text { internacionales de contabilidad, } \\
\text { las comunicaciones y el } \\
\text { desarrollo de habilidades en } \\
\text { liderazgo e investigación. }\end{array}$ \\
\hline $\begin{array}{l}\text { Universidad } \\
\text { de } \\
\text { Melbourne }\end{array}$ & Australia & $\begin{array}{l}\text { Licenciado } \\
\text { en Comercio } \\
\text { y Contador } \\
\text { Profesional }\end{array}$ & 4 años & $\begin{array}{l}\text { Asesor y asociado comercial, } \\
\text { fiscalidad, auditoría - perfil } \\
\text { gerencial }\end{array}$ \\
\hline
\end{tabular}

Fuente: elaboración propia

Analizada la anterior información se comprueba que en Estados Unidos, Europa y algunos países de América Latina - de amplia tradición en la formación contable- realizan la propuesta de los programas de estudio en el área de conocimiento contable a partir de procesos consultivos con empresarios y gremios, como se ilustra en la figura 3. De tal manera que la propuesta curricular garantice una formación pertinente y articulada para responder de mejor manera a las dinámicas sociales, empresariales, culturales y a las proyecciones gremiales y de los organismos multilaterales de los sectores económico.

A diferencia de lo que ocurre en países como Colombia, los programas de estudio se presentan más detalladamente, y se observa una amplia concentración en temas, una dispersión en las competencias y una significativa ausencia de estrategias que le permitan al estudiante la comprensión real del entorno. 


\section{- Formación Disciplinar}

Contador Público

LIcenciado en Contabilidad

Contador
Entre 4 y 5 años de duración

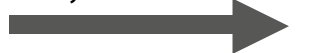

- Estándares internacionales

- Formación Integral

- Procesos consultivos con empresarios y gremios

- Garantizar formación pertinente, articulada con dinámicas sociales, empresariales, culturales.

- Parte de la praxis a la teoría.

- Efectividad relación Universidad-Empresa-Estado

Figura 3. Estado actual de la formación contable en el contexto mundial.

Fuente: elaboración propia

Lo anterior tiene relación con el enfoque de los programas, mientras que en el escenario internacional se parte de la praxis a la teoría. Dan prelación a los estudios de casos como metodología propia de los procesos de enseñanza-aprendizaje-evaluación, en Colombia este es el ámbito que más requiere ser revisado, de igual forma la concepción del plan de estudio va de la teoría a una práctica relativizada.

Las metodologías utilizadas en los programas de esta área de conocimiento están basadas en escuelas o colegios con investigaciones aplicadas, que responden al escenario social y empresarial, mientras que en Colombia la metodología está dada por medio de facultades. En el escenario internacional, se resalta en los programas del área de conocimiento estructuras curriculares que promueven una efectiva relación universidad-empresa-Estado, con el fin de que la formación en el área contable genere desarrollos en temas de investigación, innovación y competitividad. 


\section{Estado actual de la educación contable en Colombia}

Tradicionalmente en Colombia, el programa de Contaduría Pública se ha desarrollado en modalidad presencial, se resalta el programa de la Universidad Nacional de Colombia que data del año 1965 como uno de los programas más antiguos y actualmente vigente (SNIES, 2017).

Sólo hasta inicios de la década del año 2000 aparecen los programas de contaduría pública en modalidad a distancia tradicional con el propuesto por la Fundación Universitaria del Área Andina (SNIES, 2017).

Para el año 2002 nace el primer programa en modalidad virtual de la Universidad Autónoma de Bucaramanga, y posteriormente en el año 2008 el segundo programa en modalidad virtual propuesto por el Politécnico Grancolombiano. Sólo hasta el período comprendido entre 2014 y 2016 se da el gran desarrollo de los programas virtuales de contaduría pública con once programas nuevos que obtienen registro calificado y que actualmente se encuentran en funcionamiento (SNIES, 2017).

De acuerdo con el Sistema Nacional de Instituciones de Educación Superior (SNIES), al mes de abril de 2017, Colombia cuenta con 245 programas de contaduría pública con registro calificado vigente. De los cuales, el $26 \%$ corresponde a instituciones de carácter oficial con 64 registros calificados y el $74 \%$ corresponden a instituciones privadas con 181 registros calificados, como se ilustra en la tabla 4.

De los 245 programas de contaduría pública existentes, 224 son ofertados en modalidad presencial, ocho programas en modalidad a distancia tradicional y trece programas en modalidad virtual, como ilustra la siguiente tabla. 
Tabla 4. Programas activos de contaduría pública Según el SNIES.

\begin{tabular}{lllllll}
\multicolumn{1}{c}{$\begin{array}{c}\text { CONTADURIA } \\
\text { PÚBLICA }\end{array}$} & \multicolumn{2}{c}{ TOTAL SNIES } & \multicolumn{2}{c}{ SECTOR PÚBLICO } & SECTOR PRIVADO \\
\hline Presencial & 224 & $92 \%$ & 61 & $27 \%$ & 163 & $73 \%$ \\
\hline Distancia Tradicional & 8 & $3 \%$ & 3 & $38 \%$ & 5 & $62 \%$ \\
\hline Virtual & 13 & $5 \%$ & 0 & $0 \%$ & 13 & $100 \%$ \\
\hline TOTAL & $\mathbf{2 4 5}$ & $\mathbf{1 0 0 \%}$ & $\mathbf{6 4}$ & $\mathbf{2 6 \%}$ & $\mathbf{1 8 1}$ & $\mathbf{7 4 \%}$ \\
\hline Alta calidad & 30 & $100 \%$ & 7 & $23 \%$ & 23 & $\mathbf{7 7 \%}$ \\
\hline
\end{tabular}

Fuente: elaboración propia

De los programas de contaduría pública existentes, a la fecha presente, hay treinta programas acreditados, de los cuales siete se ofrecen en instituciones públicas y 23 en instituciones privadas. El $100 \%$ de programas acreditados son en modalidad presencial, con propuestas curriculares que oscilan entre 130 y 187 créditos académicos.

Por su parte, el valor de la matrícula oscila entre $\$ 2,3$ millones y $\$ 6,6$ millones por semestre, esto para las instituciones de carácter privado, dado que las oficiales establecen el valor de la matrícula de acuerdo con las condiciones socioeconómicas de cada estudiante.

En la figura 4 se ilustra la creación de nuevos programas de contaduría pública en modalidad virtual. Se evidencia una tendencia creciente entre los años 2014 a 2016, con la creación de once nuevos programas, todos activos, con estudiantes matriculados y ofrecidos por instituciones de carácter privado únicamente. 


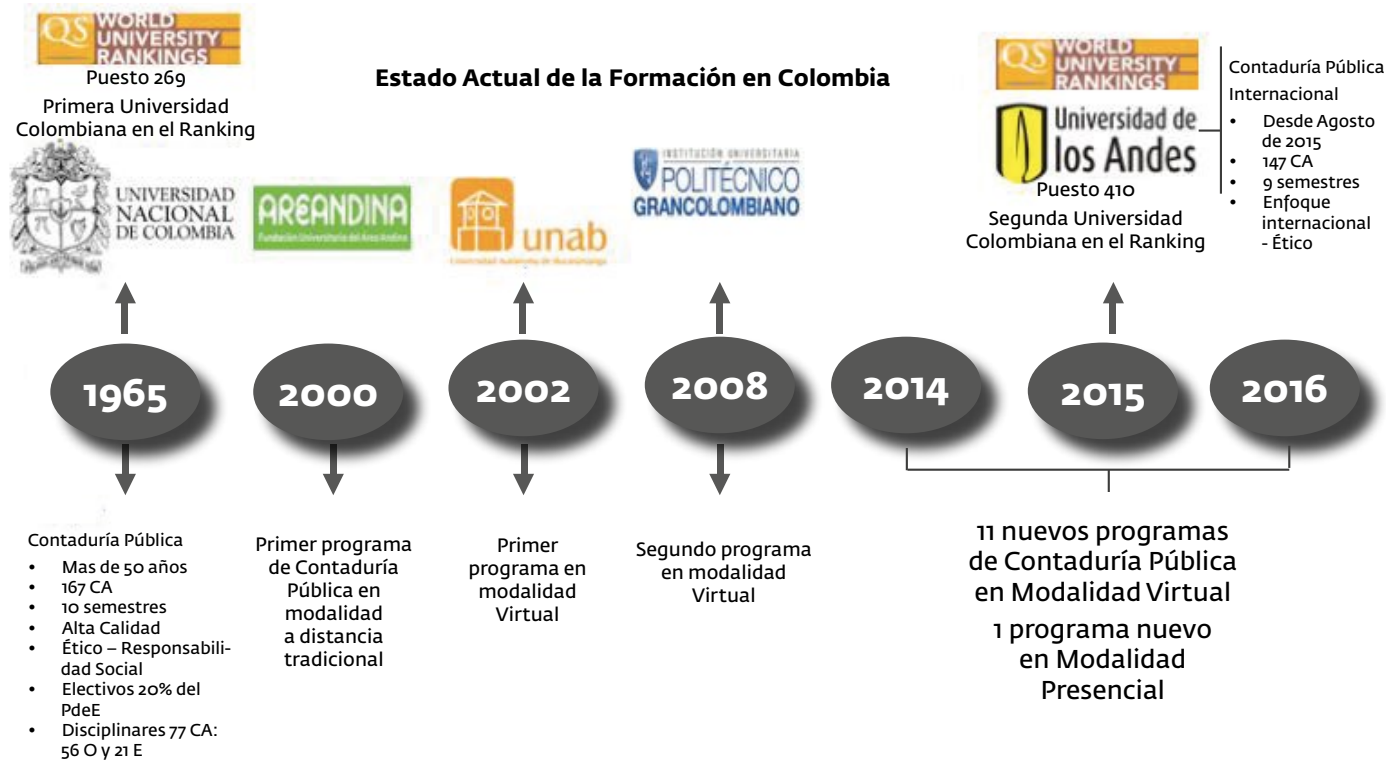

Figura 4. Desarrollo de programas de contaduría pública en Colombia Fuente: elaboración propia

A su vez, los últimos registros calificados otorgados a nuevos programas de contaduría pública entre el año 2014 a 2016 muestra tendencia a la eficiencia en cuanto al número de créditos académicos (CA), con programas tendientes a Ios 140 CA. A excepción de tres programas propuestos por ciclos propedéuticos que son los que mayor número de créditos proponen, uno de ellos con 172 CA.

Es importante y necesario resaltar que el $100 \%$ de los registros calificados vigentes y activos en modalidad virtual, para el programa de contaduría pública, corresponden a instituciones de educación superior del sector privado, dejando en evidencia la ausencia total del sector educativo oficial. 


\section{Rasgos y características principales de la oferta académica nacional}

Para el análisis de los rasgos y características de oferta académica actual del programa profesional de contaduría pública, en modalidad virtual en el país, se toman como base los trece programas existentes, activos y con registro calificado vigente de acuerdo con el SNIES al mes de abril de 2017 y la información obtenida de las páginas web institucionales a esta misma fecha.

De los trece programas analizados, tres de ellos se ofrecen por ciclos propedéuticos y presentan 150, 172 y 155 créditos académicos, con periodicidad de admisión semestral y trimestral. Los restantes diez programas son terminales y presentan entre 138 y 160 créditos, identificándose una tendencia en los registros calificados otorgados en los dos últimos años hacia la disminución del número total de créditos académicos, pues seis de ellos presentan entre 138 y 144 créditos académicos.

Tabla 5. Programas activos de contaduría pública en modalidad virtual en Colombia.

\begin{tabular}{|c|c|c|c|c|c|c|}
\hline Institución & $\begin{array}{l}\text { Registro } \\
\text { calificado }\end{array}$ & $\frac{0}{0}$ & & Períodos & Matrícula & Municipio \\
\hline $\begin{array}{l}\text { Universidad de } \\
\text { Manizales }\end{array}$ & 09/07/2014 & 138 & 8 & Semestral & 1.410 .000 & Manizales \\
\hline $\begin{array}{l}\text { Universidad Autónoma } \\
\text { de Bucaramanga }\end{array}$ & 03/08/2016 & 160 & 9 & Semestral & 2.236 .000 & Bucaramanga \\
\hline $\begin{array}{l}\text { Universidad Tecnológica } \\
\text { de Bolívar } \\
{ }^{\star} \text { CP }\end{array}$ & 03/12/2014 & 150 & 9 & Semestral & 2.800 .000 & Cartagena \\
\hline $\begin{array}{l}\text { Fundación Universitaria } \\
\text { María Cano }\end{array}$ & 08/04/2015 & 140 & 12 & Cuatrimestral & 1.579 .000 & Medellín \\
\hline $\begin{array}{l}\text { Politécnico } \\
\text { Grancolombiano }\end{array}$ & 08/04/2015 & 144 & 9 & Semestral & 1.499 .000 & Bogotá \\
\hline $\begin{array}{l}\text { Fundación Universitaria } \\
\text { CEIPA }\end{array}$ & 09/05/2014 & 160 & 4 & Anual & $147.000 \mathrm{CA}$ & Sabaneta \\
\hline
\end{tabular}




\begin{tabular}{|c|c|c|c|c|c|c|}
\hline Institución & $\begin{array}{l}\text { Registro } \\
\text { calificado }\end{array}$ & $\frac{0}{\frac{0}{2}}$ & & Períodos & Matrícula & Municipio \\
\hline $\begin{array}{l}\text { Fundación Universitaria } \\
\text { Católica del Norte }\end{array}$ & $20 / 01 / 2016$ & 140 & 8 & Semestral & 2.281 .000 & $\begin{array}{l}\text { Sta. Rosa } \\
\text { de Osos }\end{array}$ \\
\hline Universidad EAN & 03/01/2014 & 144 & 9 & Semestral & 3.296 .000 & Bogotá DC \\
\hline $\begin{array}{l}\text { Corporación Universitaria } \\
\text { Iberoamericana }\end{array}$ & $14 / 01 / 2016$ & 150 & 10 & Cuatrimestral & 2.129 .000 & Bogotá DC \\
\hline $\begin{array}{l}\text { Corporación } \\
\text { Universitaria Remington }\end{array}$ & 07/09/2015 & 144 & 9 & Semestral & 1.632 .275 & Medellín \\
\hline $\begin{array}{l}\text { Fundación Escuela } \\
\text { Colombiana de } \\
\text { Mercadotecnia } \\
\text { - ESCOLME }\end{array}$ & 28/11/2014 & 160 & 10 & Semestral & 2.212 .763 & Medellín \\
\hline $\begin{array}{l}\text { Corporación } \\
\text { Universitaria Americana } \\
{ }^{\star C P}\end{array}$ & $16 / 12 / 2014$ & 172 & 10 & Semestral & 1.923 .718 & Barranquilla \\
\hline $\begin{array}{l}\text { Universitaria Virtual } \\
\text { Internacional } \\
{ }^{\star} \mathbf{C P}\end{array}$ & $12 / 05 / 2015$ & 155 & 18 & Trimestral & $\begin{array}{l}870.000 \\
\text { Trim }\end{array}$ & Bogotá DC \\
\hline
\end{tabular}

Fuente: elaboración propia

Las instituciones que ofrecen el programa de contaduría pública en modalidad virtual, orientan la cobertura desde las zonas o regiones donde tienen presencia, ninguna de las instituciones cuenta con presencia física con cobertura nacional.

El tiempo que propone cada institución para el desarrollo del programa de contaduría pública varía entre tres y cinco años. Se evidencia igualmente una tendencia hacia la menor inversión de tiempo, lo cual incluye a los programas de contaduría pública en modalidad virtual por ciclos propedéuticos.

Como seaprecia en la tabla 5, los programas de contaduría pública en modalidad virtual proponen en su plan de estudios entre 138 y 172 créditos académicos y los precios de matrícula oscilan entre \$1.4 millones y \$3.3 millones y el valor de la matrícula para los programas de contaduría pública en modalidad virtual 
se establecen desde cada institución de acuerdo con el período académico propuesto, bien sea semestral, trimestral o cuatrimestral. A excepción de la Fundación Universitaria CEIPA que es la única institución que establece el cobro de la matrícula por crédito académico que tiene valor de \$147.000.

Los programas de contaduría pública propuestos en modalidad virtual, de acuerdo con la información consultada a través de las páginas web institucionales, orientan sus esfuerzos en las áreas de formación propias de la formación del contador público en contabilidad, finanzas, costos, aseguramiento, impuestos, ética, que se complementan con cursos del componente organizacional, de información, de regulación, de formación básica y sociohumanística.

Además de la formación y competencias profesionales propias de la disciplina, orientan sus esfuerzos para la formación integral de los contadores con capacidades para aportar en el proceso de gestión de las organizaciones, con elevados valores éticos como garantes de la confianza pública y su aporte social.

Tabla 6. Perfil profesional en los programas activos de contaduría pública en modalidad virtual.

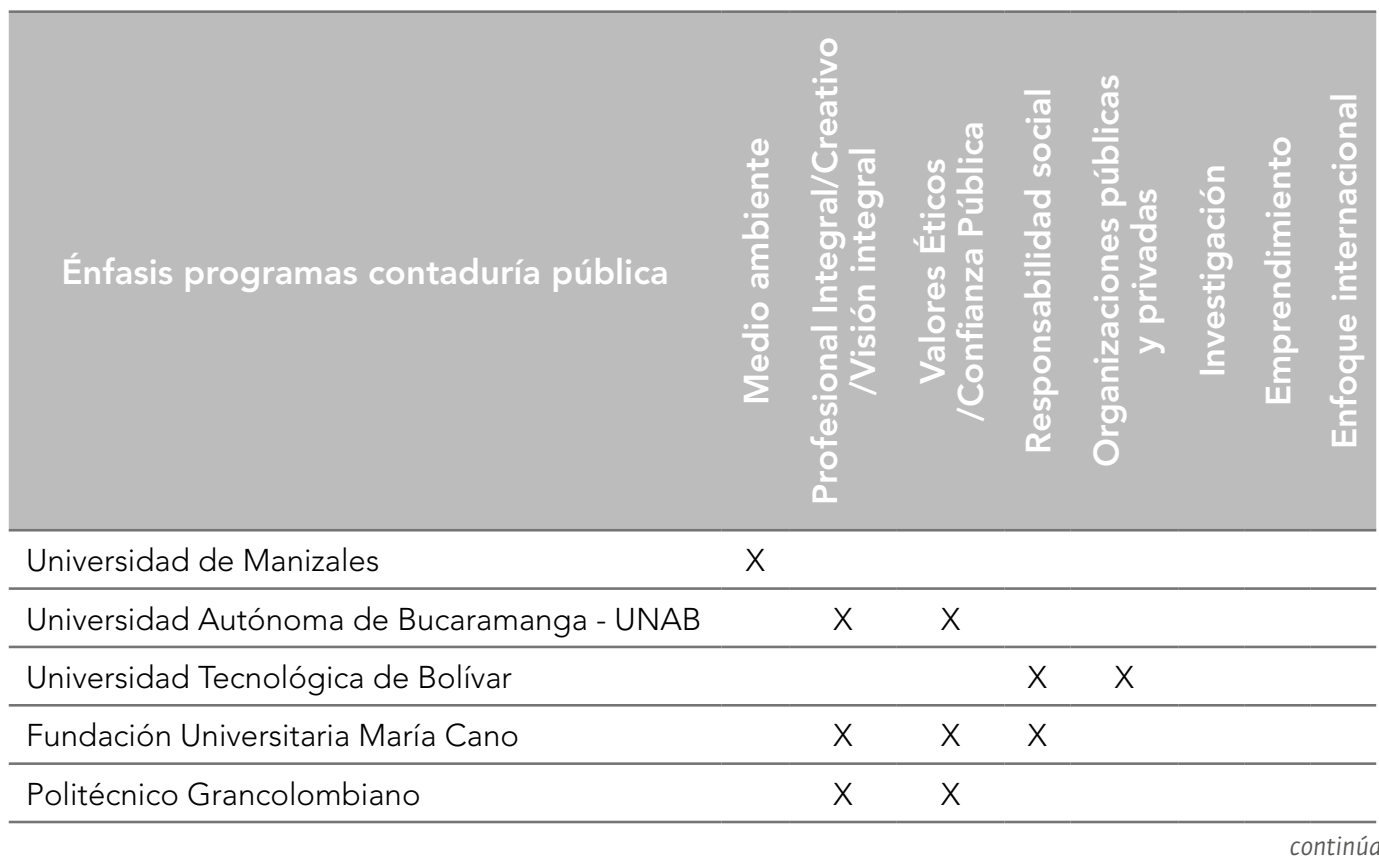




\begin{tabular}{|c|c|c|c|c|c|c|c|c|}
\hline Énfasis programas contaduría pública & 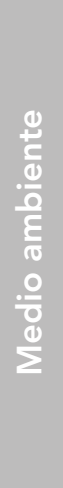 & 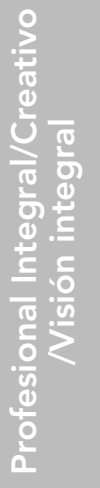 & 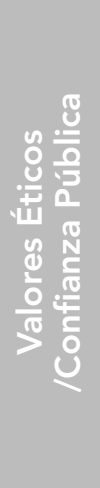 & 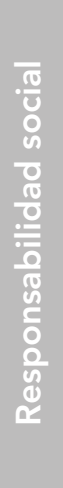 & 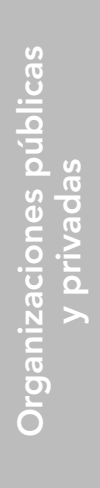 & 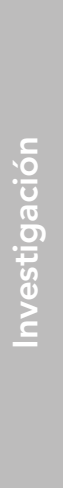 & 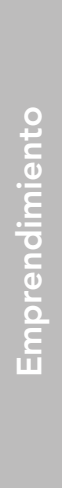 & 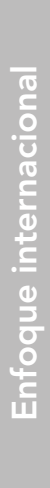 \\
\hline Fundación Universitaria CEIPA & & & $x$ & $x$ & & & & \\
\hline Fundación Universitaria Católica del Norte & & & & & & $x$ & & \\
\hline Universidad EAN & & & & & & & $x$ & $x$ \\
\hline Corporación Universitaria Iberoamericana & & & $x$ & & & & & \\
\hline Corporación Universitaria Remington & & & & $x$ & & & & \\
\hline $\begin{array}{l}\text { Fundación Escuela Colombiana de } \\
\text { Mercadotecnia - ESCOLME }\end{array}$ & & $x$ & & & & & & \\
\hline Corporación Universitaria Americana & & $x$ & $x$ & $x$ & & & & \\
\hline Universitaria Virtual Internacional & & $x$ & $x$ & & & & & \\
\hline
\end{tabular}

Fuente: elaboración propia

Respecto del componente de flexibilidad de los programas en oferta, desde los cursos electivos del programa se pudo evidenciar que muchas instituciones proponen un máximo de 8 CA, e incluso se encuentran dos programas sin créditos académicos electivos. Con excepción de los programas propuestos por el Politécnico Grancolombiano y la Corporación Universitaria Iberoamericana que proponen 12 y 13 CA respectivamente.

Los anteriores hallazgos, en términos generales, permitieron inferir cierto nivel de rigidez para la formación de los profesionales de contaduría pública a partir de los planes de estudios de los programas en modalidad virtual existentes. 


\section{La fe pública y los principios éticos en el ejercicio de la profesión}

Un aspecto fundamental e inherente a la profesión del contador público se relaciona con los sólidos principios éticos y de responsabilidad social que le corresponde observar y aplicar en el desarrollo de su ejercicio profesional. Es un garante de la "fe pública" sobre la generación, gestión y control de la información financiera y de aseguramiento de la información de las organizaciones que sirve de base a toda la comunidad, nacional e internacional, en su proceso de toma de decisiones para el desarrollo de los negocios y en el desarrollo social (Fuertes, 2018).

En este aspecto, la Junta Central de Contadores (JCC) señala en su página web, que en los últimos seis años ha impuesto 500 sanciones a profesionales de la contaduría pública del país, que van desde amonestaciones, sanciones, hasta la cancelación de la tarjeta profesional, como ilustra la siguiente tabla.

Tabla 7. Sanciones impuestas a contadores públicos, período 2012-2017.

\begin{tabular}{lccccccc}
\hline & 2012 & 2013 & 2014 & 2015 & 2016 & 2017 & TOTAL \\
\hline Suspensión & 25 & 56 & 79 & 122 & 133 & 40 & 455 \\
\hline Amonestación & 0 & 7 & 4 & 7 & 13 & & 31 \\
\hline Cancelación & 2 & 1 & 4 & 1 & 6 & & 14 \\
\hline TOTAL & $\mathbf{2 7}$ & $\mathbf{6 4}$ & $\mathbf{8 7}$ & $\mathbf{1 3 0}$ & $\mathbf{1 5 2}$ & $\mathbf{4 0}$ & $\mathbf{5 0 0}$ \\
\hline
\end{tabular}

Fuente: elaboración propia

Como se aprecia, en la medida en que se avanza en el tiempo se incrementa progresiva y significativamente el número de sanciones impuestas a los contadores públicos. Se pasan de 27 sanciones impuestas en el año 2012 a 152 sanciones en el año 2016. Para lo corrido del año 2017 se cuentan 40 sanciones. Se encontró igualmente que, para el caso de las amonestaciones, la JCC hace el correspondiente llamado de atención que queda registrado en el historial del contador. Para el caso de suspensiones se aplica la suspensión del contador hasta por doce meses; y para el caso de cancelaciones se procede con la inhabi- 
lidad definitiva del contador y en algunos casos se encontró inhabilidades por diez años para ejercer como contador público.

Como se puede apreciar en la siguiente tabla, mientras el número de contadores públicos se incrementó en un $28 \%$ al pasar de 180.094 contadores en el año 2012, a 230.246 en el año 2016, las sanciones impuestas por la JCC presentan un incremento del $463 \%$ para este mismo período de tiempo. Esto indica que en la medida en que los años han transcurrido se genera mayor incremento de las sanciones impuestas alcanzando niveles preocupantes. Este análisis se realizó para el período 2012 a 2016 por corresponder a los años terminados, en el momento de elaborar la investigación.

Tabla 8. Incremento de sanciones Vs. contadores públicos, 2012-2016

\begin{tabular}{lccc}
\hline Contadores Vs Sanciones & 2012 & 2016 & $\%$ Variación Total \\
\hline Contadores & 180.094 & 230.246 & $28 \%$ \\
\hline Sanciones JCC & 27 & 152 & $463 \%$ \\
\hline
\end{tabular}

Fuente: elaboración propia

Al revisar aleatoriamente las causas que ocasionaron las sanciones se encontraron aspectos como:

- Falta decapacidad profesional al momento deaplicar los principiosestablecidos para el reconocimiento de los hechos económicos y sus revelaciones, alterando las cifras que ilustran la situación financiera de las organizaciones.

- Falta de idoneidad en los informes presentados por revisores fiscales y auditores, relacionados con deficiencias en el aseguramiento del control interno en las organizaciones o en dictámenes incompletos que no revelan suficientemente la real situación financiera de las organizaciones.

- Faltas contra la ética al manipular cifras de los estados financieros para generar informes tributarios fraudulentos con miras a obtener beneficios tributarios o menor pago de impuestos.

- Faltas contra la ética al manipular cifras de los estados financieros para incurrir en dolo, afectando los recursos financieros de las organizaciones. 
- Faltas reiterativas por incompetencia en el desempeño de la labor del profesional de la contaduría pública.

- Desarrollo de actividades de la profesión en períodos en los cuales el contador se encuentra suspendido.

De acuerdo con la información analizada, se evidencia que es fundamental desarrollar en los estudiantes de esta disciplina la conciencia sobre la responsabilidad social que les atañe y que está implícita en su ejercicio profesional y el importante aporte que brindan a la sociedad como garantes de la confianza pública. Estas acciones afectan las decisiones de los stakeholders locales, regionales e internacionales, dado el actual contexto globalizado en que las organizaciones se desarrollan.

\section{Conclusiones}

La educación contable en Colombia se encuentra ampliamente regulada a través de la política pública, y se debe comprender desde el aporte fundamental que brinda al desarrollo social y económico de las organizaciones, la sociedad y el país. Este ha estado presente en todas las etapas de desarrollo de la humanidad, desde tiempos remotos hasta la actualidad; y está fundamentado en la generación de la confianza pública respecto de la información contable generada, la cual es fundamental para los diferentes actores intervinientes en la economía y presentes en la sociedad respecto de las decisiones que se toman.

El sistema educativo tiene el deber de formar a los profesionales de la contaduría pública que van a atender las necesidades de organizaciones, nacionales e internacionales y la sociedad en general; en consideración del desarrollo mercantil y económico en un ambiente altamente globalizado, también debe observar las tendencias del contexto internacional.

En el contexto internacional, los programas de formación profesional en contabilidad consideran las denominaciones de contador público, licenciado en contabilidad o simplemente contador, sus planes de estudio se proponen 
para una duración entre cuatro a cinco años y se centran en la formación disciplinar basada en estándares internacionales de información financiera y de aseguramiento de la información, y en la formación integral del contador, partiendo de la praxis a la teoría. La investigación aplicada en el campo de la profesión se orienta a responder las necesidades de las organizaciones desde el escenario social y empresarial.

La denominación tradicional para este tipo de programas de educación superior, en Colombia, se establece como contaduría pública y otorga la correspondiente titulación de contador público. Tradicionalmente se ha desarrollado en metodología presencial, con duración de cinco años y hasta 187 créditos académicos; pero en los últimos años ha mostrado la tendencia a la metodología virtual, especialmente entre los años 2014 a 2016 y planes de estudio tendientes a los 140 créditos académicos, de acuerdo con las tendencias en el contexto internacional.

En Colombia, los programas de contaduría pública proponen el desarrollo de competencias tanto disciplinares como de apoyo en la gestión de las organizaciones, como aporte significativo al proceso de toma de decisiones, y otro aspecto identificado es la orientación para la formación ética del profesional como garante de la confianza pública, con responsabilidad social.

Los planes de estudio para este tipo de programas se proponen por créditos académicos, entre 130 y 187 créditos. Para los últimos programas propuestos, en modalidad virtual, se apreció la tendencia a reducir el número de créditos académicos en concordancia con la tendencia en educación contable de las principales instituciones educativas del contexto mundial.

En los planes de estudio se identificó la concentración de cursos para el desarrollo de competencias disciplinares, con diseños curriculares que presentan poca e incluso nula flexibilidad. Esto se evidencia en el bajo número de créditos electivos, lo cual limita al estudiante su oportunidad de elegir como complementar su formación profesional de acuerdo con su proyecto de vida y las necesidades de la región donde se desempeña. 
Otro aspecto corresponde a los precios de matrícula, donde la mayoría de la instituciones lo establecen por período académico y no por crédito académico, lo que también se constituye en un factor limitante de flexibilidad al no permitir al estudiante establecer la matrícula de acuerdo con su proyecto de vida, sus necesidades y situación económica particular.

\section{Referencias}

Cañibano Calvo, L. (1979). Teoría actual de la contabilidad. Madrid, España: Ediciones Información Comercial Española, ICE.

Congreso de la República de Colombia. (1990). Ley 43 de diciembre 13 de 1990. Recuperado de: https://www.mineducacion.gov.co/1621/articles-104547_archivo_pdf.pdf

Congreso de la República de Colombia. (1992). Ley 30 de diciembre 28 de 1992. Recuperado de: http://www.oas.org/juridico/spanish/mesicic2_col_ley_30_sp.pdf

Congreso de la República de Colombia. (2008). Ley 1188 de abril 25 de 2008. Recuperado de: https://www.mineducacion.gov.co/1621/articles-159149_archivo_pdf.pdf

Congreso de la República de Colombia. (2009). Ley 1314 de julio 13 de 2009. Recuperado de: http://www.secretariasenado.gov.co/senado/basedoc/ley_1314_2009.html

Corte Constitucional de Colombia. (1991). Constitución Política de Colombia, 1991. Recuperado de: https://www.ramajudicial.gov.co/documents/10228/1547471/ CONSTITUCION-Interiores.pdf

Fuertes, M. (2018). El aporte del conocimiento contable en la Nueva Gestión Pública. En: W. Sánchez, R. Giraldo, M. Caballero, L. Nieto, J. Sánchez, G. De la Cruz, J. Montoya, N. Agudelo, M. Díaz, G. Hernández, K. Ortiz, H. Hurtado, M. Chica and A. Arias. (Ed.), La nueva gestión pública frente a los desafíos de Colombia en el siglo XXI. Cali, Colombia: Universidad Libre Seccional Cali. 
Fundación IFRS. (2017). Estándares IFRS. Recuperado de: https://www.ifrs.org/ https://translate.google.com.co/translate?hl=es\&sl=en\&u=https://www.ifrs. org/\&prev=search

Mejía, E. Mora, E. y Montes, C. (2013). Adscripción de la contabilidad en la estructura general del conocimiento. Cuadernos de Contabilidad, 14 (34), 159-187.

Ministerio de Educación Nacional de Colombia. (2003). Decreto 3459 de diciembre 30 de 2003. Recuperado de: https://www.mineducacion.gov.co/1621/articles-85909_ archivo_pdf.pdf

Ministerio de Educación Nacional. (2010). Decreto 1295 de abril 20 de 2010. Recuperado de: https://www.mineducacion.gov.co/1621/articles-229430_archivo_ pdf_decreto1295.pdf

Ministerio de Educación Nacional de Colombia. (2015). Decreto 1075 del 26 de mayo de 2015. Recuperado de: http://redes.colombiaaprende.edu.co/ntg/men/pdf/ decreto_1075_de_2015.pdf

Ministerio de Educación Nacional. (2017). Sistema Nacional de Información de Educación Superior, SNIES. Recuperado de: https://www.mineducacion.gov.co/ sistemasinfo/snies/

OS World University Rankings. (2018). Top Universities. Recuperado de: https://www. topuniversities.com/university-rankings 
